\title{
An assessment of the accuracy of military workforce models
}

\author{
$\underline{\text { D Oliver }}^{\text {a }}$ \\ ${ }^{a}$ Defence Lessons Program, Australian Defence Organisation, Australian Capital Territory.
}

Email:david.oliver11@defence.gov.au

\begin{abstract}
This paper describes work performed to assess the accuracy of a typical military workforce model used by the Australian Defence Organisation (ADO), and by many other military organisations, to forecast future workforce composition. While there are many published accounts describing such model construction, the author has found little evidence of work done to assess the accuracy of the models described.

The military workforce is predominantly a closed system. Recruits enter at the lowest rank and then over time move to higher ranks or leave the system. How long it takes to gain a promotion is determined by: access to training and skill acquisition; personal aptitude; imposed limits on the numbers allowed in a rank; set minimum times individuals have to spend in each rank; and whether individuals choose to promote. The main influences on the workforce system are then: the annual separation numbers; how long people take to promote from one rank to another; the annual numbers of recruits; and the composition of the starting population. From estimates of separation numbers and promotion times, workforce models can be used to evaluate recruiting plans in meeting desired future workforce numbers.
\end{abstract}

To perform the desired assessment, a model was constructed in a form that enabled it to replicate the operation of the type of model used by the ADO. The model, which is described in more detail in the body of this report, uses an entity based formulation constructed in the ARENA simulation modelling tool. The model constructed was then run using actual data for both annual separation numbers and monthly recruit intakes to determine if it could accurately replicate the targeted workforce system. The data used was collected from personnel records collected between 2003 and 2016. The initial results established that the model is a reasonable representation of reality. To test the model as it is used in practice, further forecasts were made using estimates of annual separation numbers. Typically, ADO modellers use historical average separation numbers and promotion times as inputs to their models, and so, this approach was trialled in this assessment. Additionally, some more dynamic time series based estimates were tested to see if they could improve model accuracy.

From the tests described, the following findings were made.

1. The model performs well when actual historical data is used.

2. Good estimates of promotion times can be made using common probability distribution functions and that these provide a means to assess any uncertainty in the model's results.

3. When using the historical average number of separations as inputs to the model, the model can perform poorly. For example for a rank attained only by the more skilled in the workforce, and thus of more interest to forecasters, the average error for the estimated population size when using the historical average for the separation number input is approximately $15 \%$ and the maximum error $35 \%$. When actual data is used the error is $4 \%$ and $17 \%$, respectively.

4. Separation number estimates using more complicated time series calculations, when tested, showed that these may be a means, in some circumstances, to provide more accurate and precise workforce forecasts than can be produced using the historical average.

Keywords: Military workforce planning, simulation modelling, validation, stochastic modelling 


\section{INTRODUCTION}

Military workforce models are common use (Van Utterbeeck et al. 2009, Filinkov et al. 2011, Okazawa et al. 2014, Jnitova et al. 2017), and although there is much theoretical discussion as to the efficacies of one type of model over another (Wang 2005, Reid et al. 2010, Okazawa et al. 2014, Horn el al. 2015), it is difficult to find evidence that the models work in practice. An exception to this is the work by Mehmood (2007).

The work described here aims to evaluate the type of models used by the Australian Defence Organisation.

\subsection{The Military Workforce System}

The Australian Defence Force (ADF) organises its people into vocational categories called trades (technicians, engineers, logisticians), identifying the knowledge and skills required to undertake specific tasks and duties. As knowledge is acquired and demonstrated (competence), people may progress (promote) to higher paygrades or ranks recognising the level of competence achieved. The speed at which this occurs depends on how quickly training is completed, institutional minimum time in rank restrictions and, at higher ranks, the availability of a position at the next rank. Shortages of personnel in a particular rank may also prevent promotion. Due to the specific skills and knowledge required by the military, the military workforce is restricted in who can fill positions. Most entrants to the military workforce come essentially untrained via the lowest rank (recruits). A small number of people move across trades (and possibly Services e.g. Army Aviation to Air Force) and so enter at a higher rank. Some people who have left the ADF may also decide to rejoin at their previous rank. Recruiting is an ongoing activity as new personnel are constantly needed to replenish the system as people leave. People leave or exit (separate) the ADF workforce for a variety of reasons as happens in non-military workforces.

A conceptual model of the Navy sailor workforce system is shown in simplified form in Figure 1. The Navy structure is shown as the Royal Australian Navy workforce system was chosen for this exercise. The figure shows new personnel entering the system at the "Recruit" level then the progression path to possibly reach the Chief Petty Officer rank. The size of each rank has smaller numbers than the previous as people leave over time. This type of structure is typical of organisation structures in all Service Arms of the ADF.

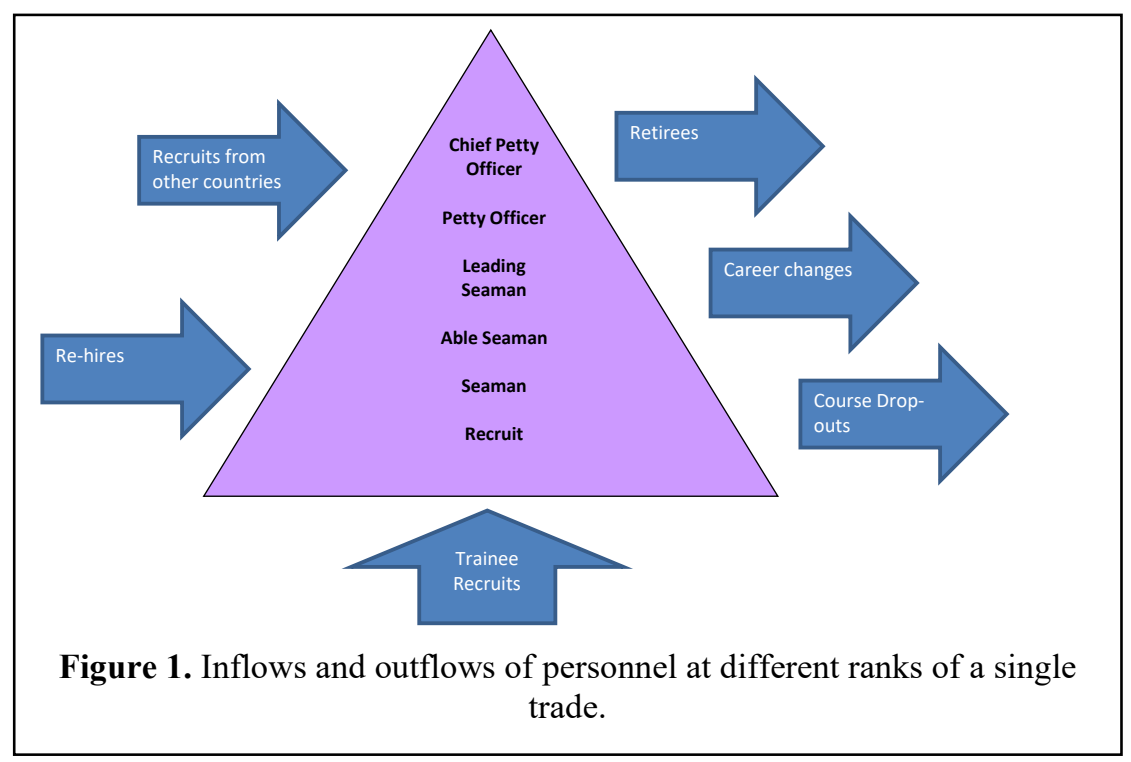

Military workforce models are characterised by their closed nature where almost all entries to higher ranks are from promotion within the organisation. This makes military workforce modelling much easier than modelling a civilian workforce where personnel can often be sourced from many other organisations.

Given the time taken to train personnel to higher levels of competency a valid workforce model provides a means to predict and manage workforce numbers over the long planning time frames involved. Without a model of some form, workforce shortages can only be avoided by overmanning and thus incurring higher salary costs with the risk that if shortages did arise, they will take many years to rectify. 


\section{MODEL DESIGN}

The model constructed is of similar form to models described by Wang (2005), Reid et al. (2010) and Horn et al. (2015). The ARENA simulation tool was chosen The model uses as inputs: the planned numbers of recruits by rank and month and year of entry; the parameters by rank with which to calculate the time which people in the system take to move up through the ranks; the parameters by rank to calculate the numbers of people who separate each year; and the workforce composition at the start of the model run. Additionally, there are constraints on the minimum number of people (minimum manning) and the maximum number of people in a particular rank at any time, during any year. The model uses monthly time steps to update the system state to be consistent with recruit intake timing.

The model design was also guided by the nature of the historical data. From studying the available data ${ }^{1}$ on the time military personnel take to promote from one rank to the next, it was found that it was firstly quite variable from person to person, but then, that it can be reasonably modelled using a common probability distribution function (pdf). For example the Petty Officer promotion time data in Figure 2 conforms quite closely to a Weibull distribution. To be able to simulate this variability, it was decided to use an entity based model (using the ARENA simulation tool), and randomly assign the time each entity (simulated person) will take to promote according to the appropriate pdf derived from historical data.

The annual separation data, like the promotion times, is also highly variable (Figure 3). From analysis of the data it was found that within a rank there is some, though small, correlation

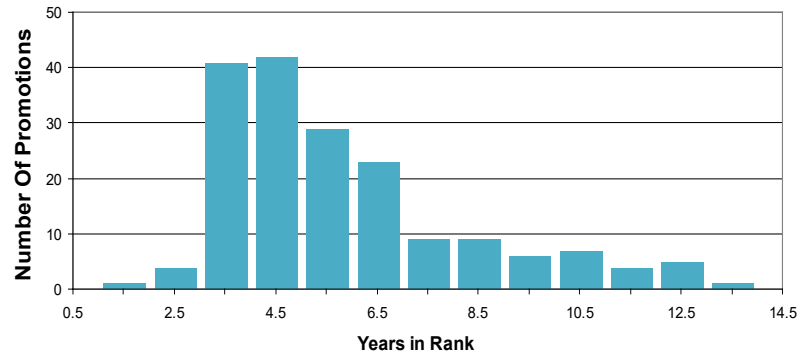

Figure 2. Frequency histogram for a Petty Officer rank promotion times.

between the number of people leaving and the numbers in the rank. Also evident from the data is the correlation across ranks though not always in phase. Based on these observations and some trialing, a model of the form of equation (1) was chosen and constructed using the 2003-2015 data and applying linear regression to estimate

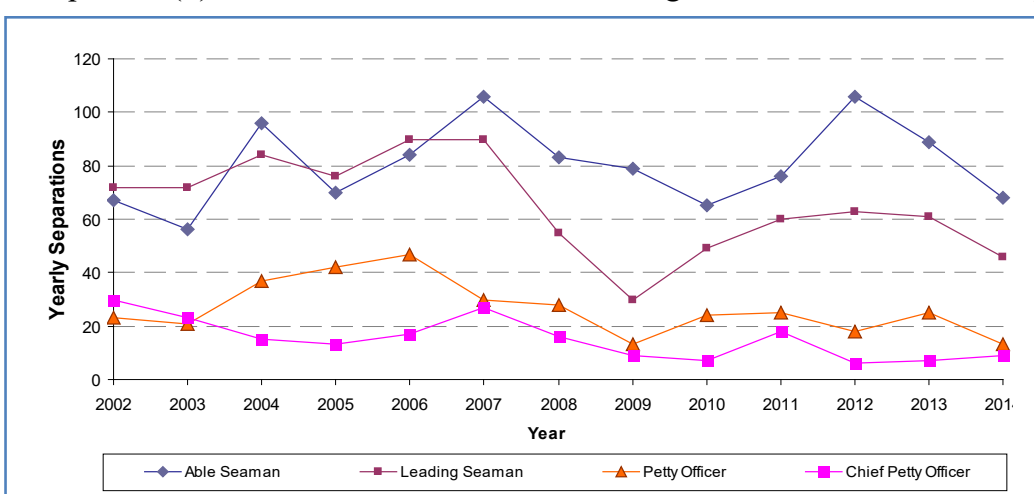
the model coefficients.

Figure 3. Historical separation numbers by rank for Trade 1.

$\mathrm{N}_{\mathrm{t}, \mathrm{r}, \mathrm{y}}=\mathrm{M}_{1} \mathrm{~S}_{\mathrm{t},(\mathrm{r} 3), \mathrm{y}}+\mathrm{M}_{2} \mathrm{~S}_{\mathrm{t},(\mathrm{r} 3), \mathrm{y}-1}+\mathrm{M}_{3} \mathrm{~S}_{\mathrm{t},(\mathrm{r} 3), \mathrm{y}-2)}+\mathrm{M}_{4} \mathrm{~S}_{\mathrm{t}, \mathrm{r},(\mathrm{y}-1)}+\mathrm{M}_{5} \mathrm{~N}_{\mathrm{t}, \mathrm{r},(\mathrm{y}-1)}+\mathrm{C}+\operatorname{err}_{\mathrm{y}}$

Table 1. Parameters used in Equation 1.

\begin{tabular}{|l|l|}
\hline $\mathrm{N}_{\mathrm{t}, \mathrm{r}, \mathrm{y}}$ & Number of personnel in trade $t$, rank $r$ in year $y$. \\
\hline $\mathrm{S}_{\mathrm{t}, \mathrm{r}, \mathrm{y}}$ & The number of separations in trade $t$, rank $r$ in year $y$ where $\mathrm{r}$ designates the Seaman rank. \\
\hline $\mathrm{M}_{\mathrm{i}}$ & Model co-efficient. $\mathrm{i}=1,2,3,4,5$ \\
\hline $\mathrm{C}$ & A constant. \\
\hline err $_{\mathrm{y}}$ & The estimated random error for year $y$. \\
\hline
\end{tabular}

\footnotetext{
${ }^{1}$ The data used was drawn from Royal Australian Navy records collected between 2003 and 2015.
} 


\section{THE TEST PROCEDURE}

To test the model two Navy trades were chosen, one with a large population (Trade 1), and one with a much smaller population (Trade 2). To demonstrate the performance of the model the Able Seaman and Petty Officer ranks were chosen. This choice provides a comparison across ranks where the forecasts for the Able Seaman rank are generally quite accurate whereas, the forecasts for higher ranks, such as the Petty Officer rank, are far less accurate. This is expected as forecast errors in the lower ranks flow through to the upper ranks.

Given that the model uses probabilistic inputs, for each test, multiple replications were made to generate a reasonable sample of possible outcomes from which to derive upper and lower bound (95 percentile level) estimates. The workforce number forecasts shown in the following test results were generated from 24 simulation replications. Repeated runs of the model showed that a better sample of forecasts would have been produced if more replications were made however, the available computer memory limited the number of replications to the 24 made.

To determine if the model is potentially able to provide an accurate representation of reality when all input data is accurate, a test was performed using actual data for all the inputs except promotion times (the starting population composition, monthly recruit numbers and monthly separation numbers). It was not possible to use actual promotion times as it would have been necessary to explicitly model named individuals and the data available did not contain this information. Thus only generic people and generic promotion times could be applied as described above.

For the next test, separations numbers each year for each trade, were set to a constant figure calculated by averaging the actual annual separations for the period simulated (2003-2015). This test was chosen as ADO workforce planners use this approach.

The final test trialed the use of equation (1) for dynamically estimating annual separation numbers. To do this actual data for pre 2003 separation numbers and personnel numbers was provided as an input.

\section{THE TEST RESULTS}

To provide a quantitative view of the performance of the model for each test, an indicative measure of accuracy, following the formulation shown in equation (2) is used. The results derived are shown in Table 2.

$$
\text { Err }=\frac{100}{k} \sum_{n=1}^{k} \frac{|((H y+L y) / 2-S y)|}{S y} \quad \mathrm{y}=1,2,3 \ldots \ldots \mathrm{k} \text { representing the years } 2003-2014 .
$$

Where the parameter $\mathrm{S}_{\mathrm{y}}$ is the actual annual number of separations for year $\mathrm{y}, \mathrm{H}_{\mathrm{y}}$ is the forecast maximum for year $\mathrm{y}$, and $\mathrm{L}_{\mathrm{y}}$ is the forecast minimum for year $\mathrm{y}$.

Table 2. Indicative Model Accuracy

\begin{tabular}{|l|l|l|}
\hline \multicolumn{1}{|c|}{ Trade and Rank } & \multicolumn{1}{|c|}{ Scenario } & \multicolumn{1}{|c|}{ Error (Err) } \\
\hline Trade 1 - Able Seaman & Actual separation data & $1.4 \%$ \\
\hline & Average separation number for period 2003-2014 & $1.7 \%$ \\
\hline & Equation 1 estimates & $1.7 \%$ \\
\hline Trade 1 - Petty Officer & Actual separation data & $7.6 \%$ \\
\hline & Average separation number for period 2003-2014 & $16.3 \%$ \\
\hline Trade 2- Able Seaman & Equation 1 estimates & $7.2 \%$ \\
\hline & Actual separation data & $3.7 \%$ \\
\hline & Average separation number for period 2003-2014 & $5.9 \%$ \\
\hline Trade $2-$ Petty Officer & Equation 1 estimates & $11.1 \%$ \\
\hline & Actual separation data & $9.3 \%$ \\
\hline & Average separation number for period 2003 - 2014 & $11.6 \%$ \\
\hline & Equation 1 estimates & $18.4 \%$ \\
\hline
\end{tabular}


From the data shown in Table 2, the Trade 1 Able Seaman forecasts would seem to be consistently accurate irrespective of the separation inputs used. The Trade 2 Able Seaman forecasts are not as accurate when using actual data and are significantly less so when using the separation estimates. As expected, the Petty Officer forecasts are not as accurate as those for the Able Seaman ranks, except for the Trade 1 forecast using equation 1. When applied to Trade 2 the equation (1) formulation does not provide any advantage.

Figures $4-9$ show some of the forecasts when graphed. These would seem to visually confirm the error measures in table 2. However the figures show, which is not obvious in table 2 data, how large the difference between the forecast and actuals can be in any year and that these differences can be significant.

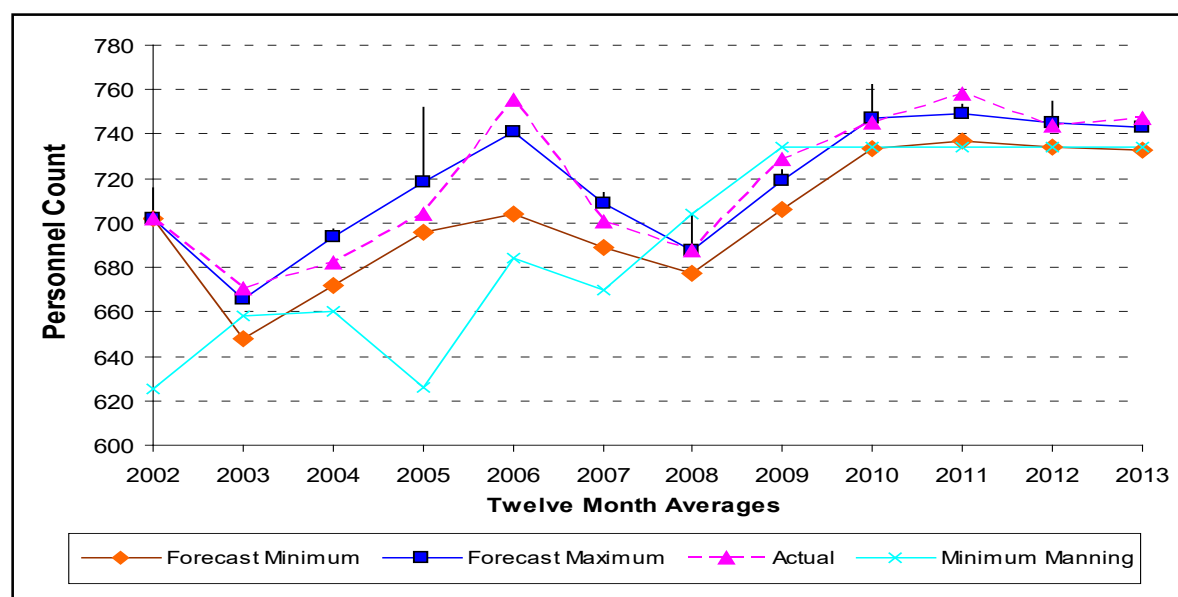

Figure 4. Able Seaman forecast for Trade 1 using actual separation data

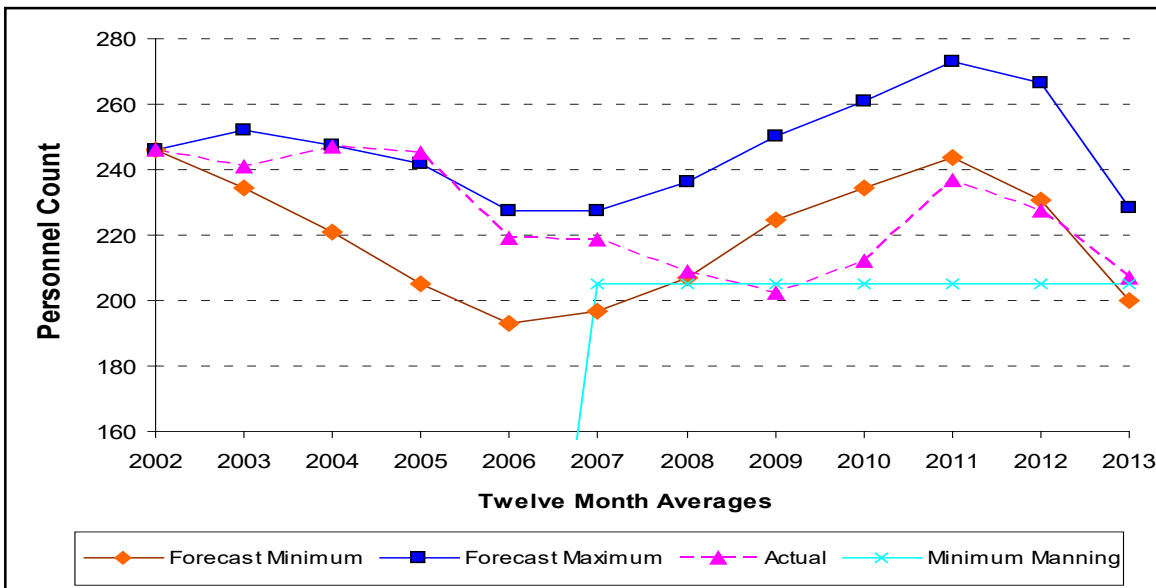

Figure 5. Petty Officer forecast for Trade 1 with actual separation data

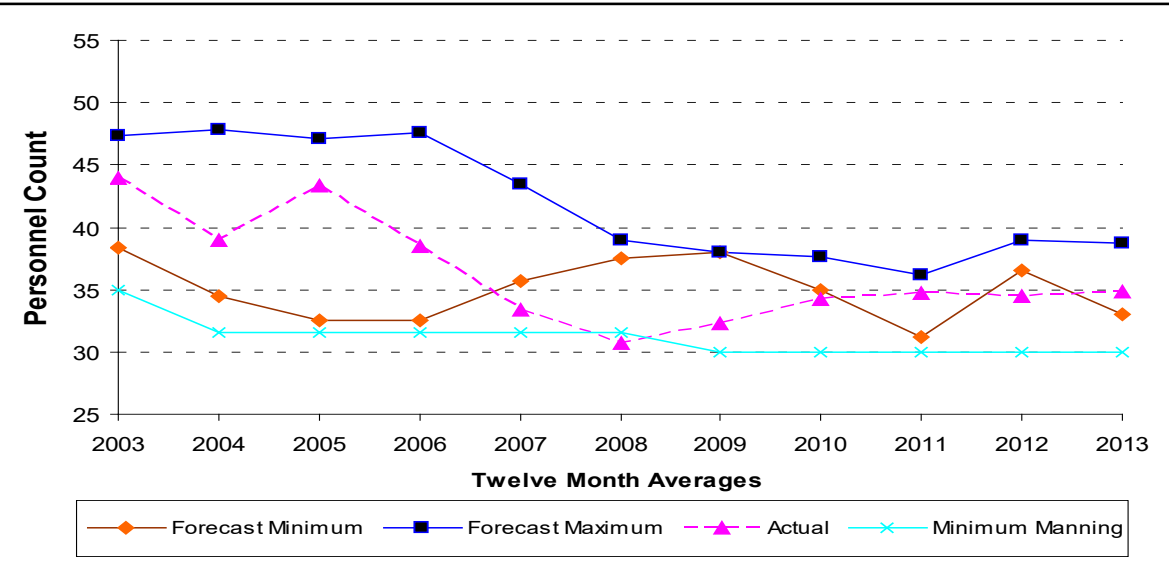

Figure 6. Petty Officer forecast for Trade 2 with actual separation data 


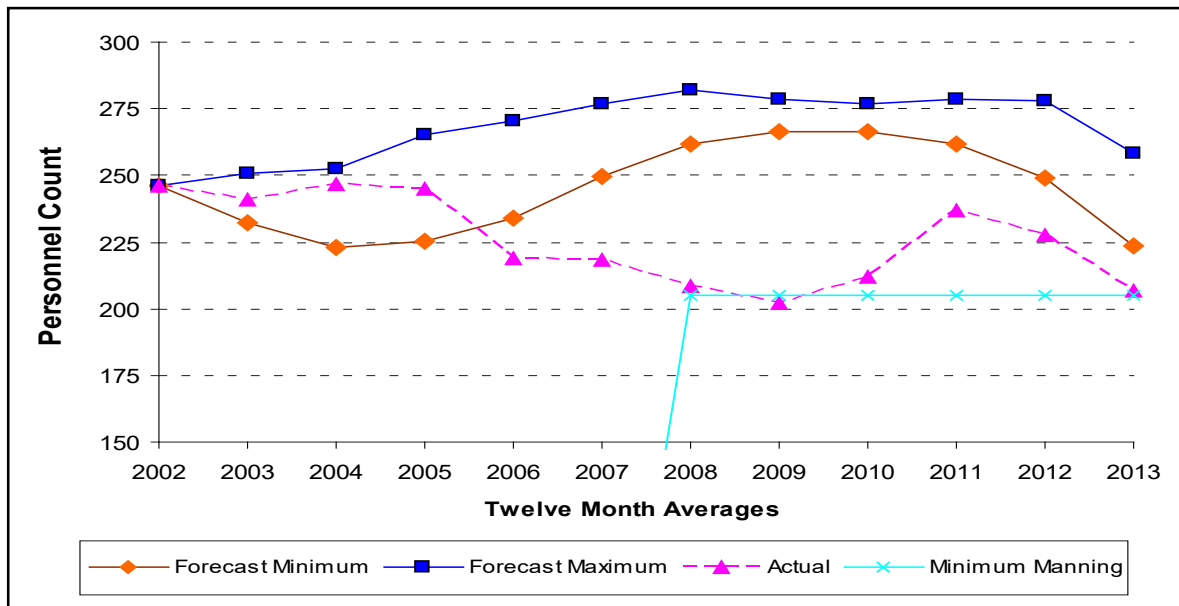

Figure 7. Petty Officer forecast for Trade 1 with average separations

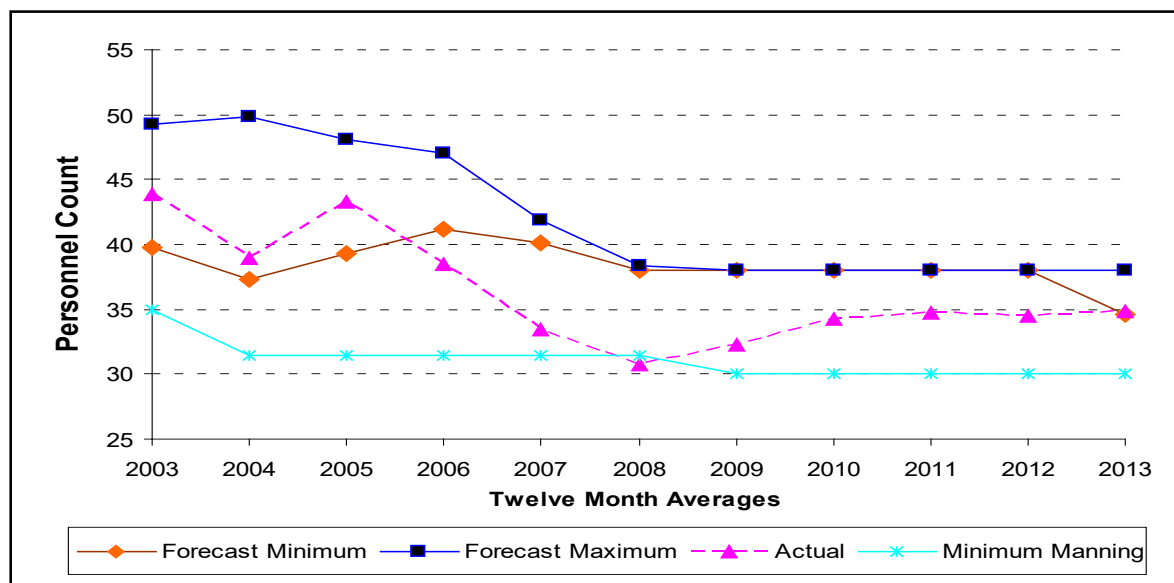

Figure 8. Petty Officer forecast for Trade 2 with average separations

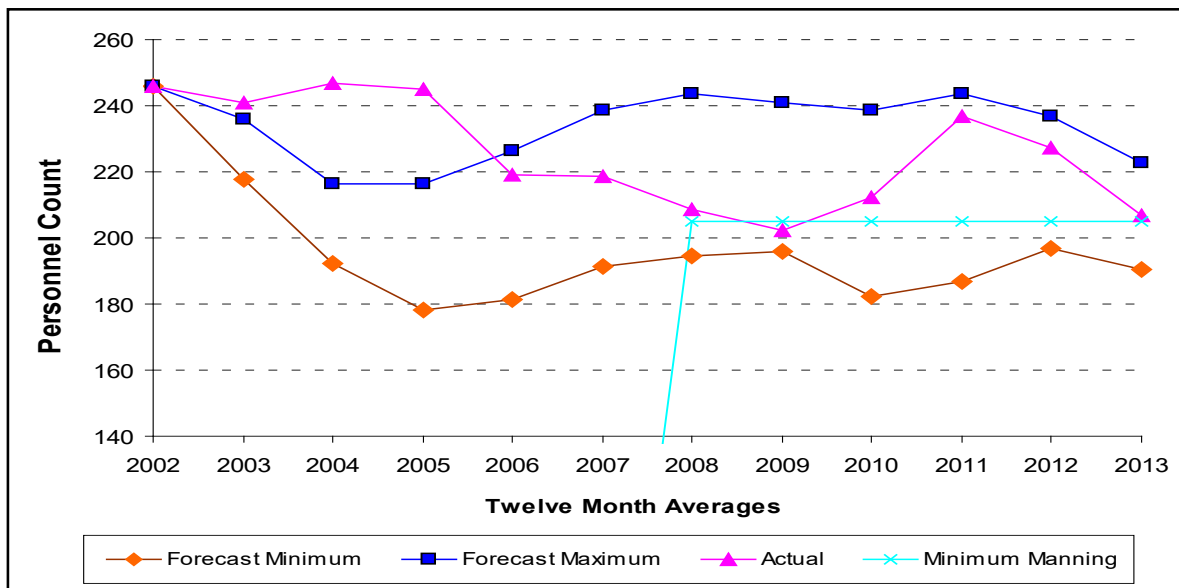

Figure 9. Petty Officer forecast for Trade 1 with equation 1 separations 
Oliver, An assessment of the accuracy of military workforce models

\section{CONCLUSION}

The test results show that the model trialed can potentially provide suitably accurate forecasts. From this analysis whether it does in practice, is dependent on how well the input data, particularly the separation estimates, reflect what actually occurs. In some circumstances it may be possible to generate practically usable forecasts by simply using the historical annual average number of separations as an input, in others, a more sophisticated estimate will be required. From the forecasts produced, the use of a pdf to generate promotion time estimates has been shown to be an acceptable approach and that generally the model seems to be able to accurately forecast the lower ranks.

The model used in this report demonstrates the utility of the modelling technique used. Being able to incorporate the variability in the times taken by people to promote, helps to better reflect reality. Being able to include this and the chance variations in yearly separation numbers to provide lower and upper bound forecasts, provides greater awareness of the accuracy limitations of the model. And being able to apply rules and calculations as needed, such as the dynamic calculations used here to estimate annual separation numbers, allows the needed control over the model's operation.

\section{ACKNOWLEDGEMENTS}

The author acknowledges the support from the Directorate of Workforce Modelling, Forecasting and Analysis in the Australian Defence Organisation in providing the data used in this paper.

\section{REFERENCES}

Horn, M., Elgindy, T. and Gomez-Iglesias, A. (2015). Strategic workforce planning for the Australian Defence Force. Journal of the Operational Research Society, 67(4), 664-675.

Jnitova, V., Elsawah, S. and Ryan, M. (2017). Review of simulation models in military workforce planning and management context. Journal of Defense Modeling and Simulation, 14(4), 447-463.

Mehmood, A. (2007). Application of Systems Dynamics to Human Resource Management of the Canadian Naval Reserves. Proceedings of the 2007 International Conference of the Systems Dynamics Society, Boston, USA, 29 July-2 August.

Okazawa, S., Moorehead, P., Jesion, A. and Isbrandt, S. (2014). Statistical Validation of a new Python Based Military Workforce Simulation Model. The Proceedings of The International Conference on Analytics Driven Solutions, 147, Ottawa, Canada, 29-30 September.

Reid, W., Riding, M., \& Taylor, J. (2010). A Review of Discrete Event Simulation in Training Pipeline and Workforce Modelling, Defence Science and Technology Organisation, DSTO-TN-0946.

Van Utterbeek, F., Pastijn, G., Van Acker, G. and Van Loock, R. (2009). Computer Simulation and Markov Chain Modelling for the HRM in the Belgium Defence. North Atlantic Treaty Organisation.

Wang, J. (2005). A Review of Operations Research Applications in Workforce Planning and Potential Modelling of Military Training. Defence Science and Technology Organisation, DSTO-TR-1688. 